\title{
Model Simplification on Energy and Comfort Simulation Analysis for Residential Building Design in Hot and Arid Climate
}

\author{
Sara Elhadad ${ }^{1,2,3, *}{ }^{\mathbb{C}}$, Chro Hama Radha ${ }^{4}$, István Kistelegdi ${ }^{1,5}$, Bálint Baranyai ${ }^{1,5}$ and \\ János Gyergyák ${ }^{6}$ \\ 1 Energia Design Building Technology Research Group, Szentágothai Research Centre, Ifjúság útja 20, \\ H-7624 Pécs, Hungary; kistelegdisoma@mik.pte.hu (I.K.); balint.baranyai@mik.pte.hu (B.B.) \\ 2 Department of Architecture, Faculty of Engineering, Minia University, Minia 61111, Egypt \\ 3 Marcel Breuer Doctoral School, Faculty of Engineering and Information Technology, University of Pécs, \\ Boszorkány u. 2, H-7624 Pécs, Hungary \\ 4 Technical College of Engineering, City Planning Department, Sulaimani Polytechnic University, Sulaimani \\ Polytechnic University, Sulaymaniyah 46001, Iraq; chro.radha@spu.edu.iq \\ 5 Department of Building Constructions and Energy Design, Faculty of Engineering and Information \\ Technology, University of Pécs, Boszorkány út 2, H-7624 Pécs, Hungary \\ 6 Department of Architecture and Urban Planning, Faculty of Engineering and Information, Technology, \\ University of Pécs, Boszorkány u. 2, H-7624 Pécs, Hungary; gyergyak.janos@mik.pte.hu \\ * Correspondence: sarareda@mu.edu.eg; Tel.: +0036-705590080
}

Received: 14 March 2020; Accepted: 10 April 2020; Published: 12 April 2020

\begin{abstract}
Accurate building physics performance analysis requires time-consuming, detailed modeling, and calculation time requirement. This paper evaluates the impact of model simplifications on thermal and visual comfort as well as energy performance. In the framework of dynamic zonal thermal simulation, a case study of a residential building in hot climate is investigated. A detailed model is created and simplified through four scenarios, by incrementally reducing the number of thermal zones from modeling every space as a separate zone to modeling the building as a single zone. The differences of total energy and comfort performance in the detailed and simplified models are analyzed to evaluate the grade of the simplifications' accuracy. The results indicate that all simplification scenarios present a marginal average deviation in total energy demand and thermal comfort by less than $20 \%$. Combining rooms with similar thermal features into a zone presents the optimal scenario, while the worst scenario is the single-zone model. Results showed that thermal zone merging as a simulation simplification method has its limitations as well, whereas a too intensive simplification can lead to undesired error rates. The method is well applicable in further early-stage design and development tasks, specifically in large-scale projects.
\end{abstract}

Keywords: Model simplifications; Thermal and visual comfort; Energy performance; IDA ICE; Residential building

\section{Introduction}

High consumption of energy is unavoidable at a global scale [1-6]. It measures the economic success of a given country. The operation of residential and commercial buildings attributes one third of the world's energy consumption [7]. Thus, there is great potential for decreasing global energy consumption through improving the building design [8]. All advanced countries concerned on building-energy problem in various ways to preserve the energy sources and to use energy in a rational way [9]. Based on the U.S. Department of Energy report, buildings are attributed to the 
majority of total annual energy consumptions and greenhouse gas emissions by the range of $40 \%$ to $50 \%[10,11]$, and similar results are shown in Europe [12]. Thus, different supranational and national initiatives, regulations, and different programs of private sectors such as CASBEE, LEED, BEEAM, DGNB, and others identify the parameters and standards to assess buildings' sustainability level and to minimize energy use. The role of appliances and residents' behaviors of users should be taken into account in sustainable building design as this role is strictly connected to energy savings and indoor comfort $[13,14]$. Becherini et al. [15] suggested and modeled several scenarios through which occupant behavior and thermal coating can contribute to the thermal performance of the building. Proper implementation of the framework, materials, knowledge, and system from design stage to construction and operation stages is required to obtain efficient buildings. The "Integrated Building Design" approach [16] is one of the possible solutions to integrate all these elements in the building sector.

Building-energy simulation is an essential support tool to design and commission green buildings. Many available, validated building-energy simulation tools, as Energy Plus, IDA ICE, TRNSYS, BLAST, ESP-r, Radiance, DOE-2 and eQUEST promise high accuracy level and effectivity for comprehensive simulation of building designs $[17,18]$, but they require detailed input for model analysis, composing of zero thickness partitions or walls between thermal zones [19]. The operation and input of building-energy simulation parameters are quite complex [20], including geometric modeling, division of thermal zones, software selection, and selection of meteorological data. Geometric modeling represents the first stage of simulation and often consumes about half of the time of the simulation procedure [21]. Thus, simplification of geometric modeling is considered to be one of the most crucial way to enhance the simulation process. Converting a detailed model back to the spatial model is a complex task for the user and represents some of unfortunate challenges [19]. Despite the proliferation of several building-energy analysis tools in recent years, architects still face difficulties to use the basic tools of energy analysis [22]. The outputs confirmed that the majority of energy simulation tools are not appropriate for the working needs and methods of architects [23-25]. Usually, simplifications occur during translating real building geometry into an energy simulation model due to the lack of modeler software, or model simplifications serve the reduction of computational effort and calculation time. Though some previous studies such as Liu and Henze [26], Westphal and Lamberts [27] and Capozzoli et al. [28] investigated the effects of simplifications on the energy analysis of buildings, it is often underestimated or neglected. Therefore, it is essential to develop a simplification methodology of building physics modeling tools to reduce time and costs of thermal and lighting building simulations, without adverse impact on the quality of results. Complex building geometries are often simplified to perform energy performance simulation [29]. Zhao et al [20] identified three common types of geometric model simplifications as follows:

(A) Calculating the load for one floor and multiplying it based on the number of floors,

(B) Simplifying the fenestration of modeling (e.g., merging windows in one space's façade),

(C) Reducing the number of internal thermal mass and thermal zones of the building.

Several studies have examined the effect of model simplification on the result accuracy. Amitrano et al. [30] investigated the effect of the level of detail on the accuracy of the energy simulation in office buildings. Their study concluded that more detailed geometry can enhance the reliability of simulation by 5 to $15 \%$. Picco and Marengo [16] assessed the effect of different simplifications in building construction types, thermal zoning, and building obstructions, for instance. The findings showed that strong simplifications on the building geometries do not make significant change on the outputs, compared to the detailed model. Bosscha [31] applied a sensitivity analysis by varying the material properties, geometry, and heating, ventilations and air conditioning (HVAC) settings to compare the accuracy of the calculations with the detailed model. The results concluded that the increase in accuracy obtained by more detailed zoning and geometry is highly relying on the HVAC simulation type. Korolija and Zhang [32] compared the predicted annual energy use of the detailed model in which every room was modeled as a separate zone with a simplified model, in which each floor is was modeled as a single 
zone. The output results showed that thermal zoning simplifications decreased the simulation time by $30 \%$ and the mean absolute error of annual heating demand was $10.6 \%$. Klimczak et al. [33] explored the effect of model simplifications on the quality of energy simulation results of a residential building case. The simplifications consisted of the reduction of thermal zones and internal walls, removal of shading elements, and calculations were carried out in different iterations. The findings showed that the exclusion of the shading devices on the south façade had a considerable effect, thus, in future studies this simplification should not be applied. Heo [34] estimated the impacts of internal load, scheduling, and thermal zoning simplifications for domestic buildings in the United Kingdom. They concluded that the differences in annual heating demand are $26 \%$ and $17 \%$ in the simplification with one single zone for the entire dwelling and one thermal zone per floor, respectively. Dipasquale et al. [35] studied the impact of defining the physical and geometric characteristics of buildings, such as the presence of internal walls, thermal capacity, thermal bridges, the gross or net surfaces, and the number of zones during the modeling stage for heat load assessment. The findings of these results concluded that the reduction of the number of zones has the highest effect on the loads, almost $22 \%$ in the cooling demand and $12.5 \%$ in heating demand. Chatzivasileiadi et al. [19] explored the impact of simplifying the complex geometries through a systematic analysis of different test cases on the accuracy of energy performance simulation results. The results concluded that orthogonal prisms as simplified surrogates for buildings should be avoided where it is possible, as it showed the worst-case scenario. Akkurt et al. [36] concluded that the simplification of geometry is often unavoidable for use in building-energy performance simulation, but inaccuracies resulted from oversimplification in some geometrical characteristics must be avoided. Zhao et al. [21] investigated the appropriate level of geometric modeling simplification through thermal zone, typical floor and fenestration in energy analysis for office buildings and they found that the more accurate case is modeling the exterior wall in regarding to internal edge. Samuelson et al [37] assessed the accuracy of 18 design-phase building-energy models to enhance the simulation predictions compared to measured energy data.

Despite the valuable results of the aforementioned studies, they just evaluate the impact of model simplification on energy simulation in residential buildings or in office types. The impacts of modeling simplification on the thermal comfort analysis are usually not investigated properly. A study of Korolija and Zehan [32] analyzed the effect of modeling simplification on thermal comfort analysis, but with a different method and focus as they considered one simplification scenario of treating each floor by a single zone and they assessed the thermal comfort performance through annual operation of carbon emission and overheating risk. Consequently, it can be stated that there is no study about the effect of model simplifications on the thermal and visual comfort published yet.

Accurate energy and thermal comfort analysis of buildings requires a lot of time, especially in complex cases it may require up to several weeks. Minimizing the required time of analysis is necessary to be compatible with design duration. Therefore, the main aim of this paper is to assess the impact of model simplifications through different scenarios considering the simulation time, modeling time, and accuracy level of the derived results in both energy demand and thermal comfort in residential houses. The paper evaluates the impact of simplifications by comparing the simulation outputs of the detailed reference model and the simplified models with incremental reduction in the number of thermal zones, until the whole house is modeled as a single zone. Moreover, the investigations explore what level of simplified thermal zoning is required to support energy and thermal comfort analysis of residential buildings. The study is carried out in the simulation framework of IDA ICE, and it also identifies the optimal scenario of the proposed simplification scenarios.

\section{Model Simplification Methodology}

This study examines the impact of reducing the number of thermal zones on the prediction accuracy of energy and comfort of residential buildings. A thermal zone represents the division of a dwelling for the convenient calculation of the energy and thermal comfort simulation of the building. The thermal properties and parameters are relatively consistent in the same thermal zone. Obviously, 
to get more accurate results of energy and thermal comfort, the simulation model should be more accurate regarding the number of modeled thermal zones of the building, but at the same time it would need more calculation time and, as a result, modeling work expenses. Many countries have provided relevant regulations for the division of thermal zones of the buildings. American National Standards Institute / American Society of Heating, Refrigerating and Air-Conditioning Engineers (ANSI/ASHRAE) 90.1 [38] reported that multiple spaces can be represented as one thermal zone with the following requirements: the usage of the spaces, the air conditioning and heating systems applied in the spaces and the orientation of the exterior walls and windows should be the same. The Building Research Establishment Ltd. [39] stated that a thermal zone is an area that has the same set points for cooling and heating, identic operating times of the plant, the same ventilation provisions and set-back conditions. In addition, they should be served by the same primary plant and terminal device type. The Canadian standard EE4 [40] stipulates that a thermal zone must have the following features: (1) same air conditioning system and heating with similar operations and functions, and similar heating and cooling loads; (2) the surrounding and the internal space should be distributed into different thermal zones; (3) rooms for laundry, equipment, power distribution, corridors, cloakrooms, and stairs cannot be modeled as a single partition.

For the purpose of the model simplifications, a multifamily house as a reference is proposed, representing a generic, typical residential building type in the largest building sector of the world. This reference building model is derived form an existing, common residential house, built in 2005 in New Minia, Egypt at 30.73 E longitude, $28.08 \mathrm{~N}$ latitude (Figure 1). The building consists of nine apartments. The ground floor is represented by one apartment and consists of a lounge, dining room, bathroom, and kitchen, with the total floor area of $180 \mathrm{~m}^{2}$. Each floor of the repeated floors consists of two identical apartments, with $220 \mathrm{~m}^{2}$ net floor area. Every apartment includes reception, master bedroom, two children rooms, bathroom, and kitchen as shown in Figure 1 and occupied by a couple with two children based on the real evaluation from the field. The composition of building elements was used on the basis of the Egyptian standards, as shown in Table 1. IDA ICE has been used to simulate thermal and visual comfort as well as energy performance in a detailed model about the reference building and in several simplification scenarios, whereas the reference model is modified according to the simplification concepts. Table 1 presents an overview of the major parameters and input data.
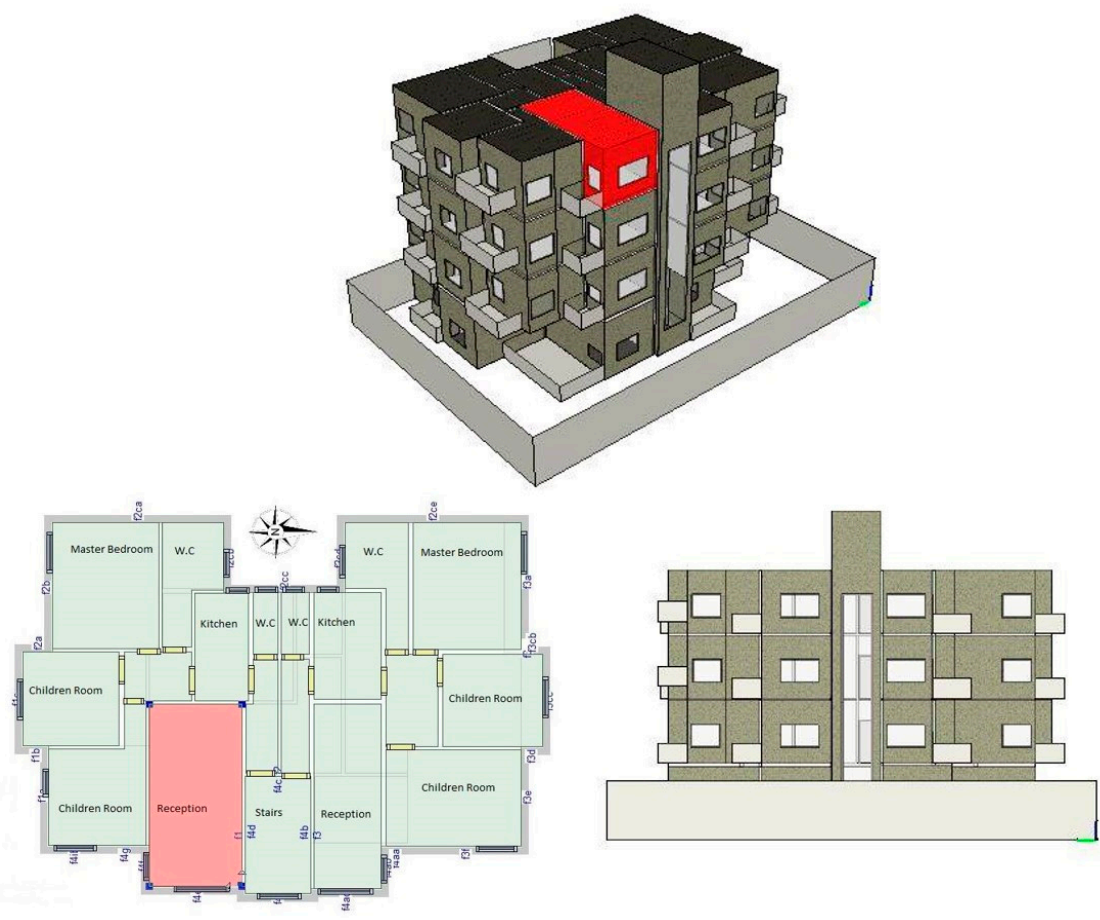

Figure 1. Generic residential building as a reference for model simplification tests. 
Table 1. Boundary conditions for the simulation.

\begin{tabular}{|c|c|c|}
\hline Boundary Conditions & \multicolumn{2}{|c|}{ Model Characteristics } \\
\hline Location & \multicolumn{2}{|c|}{ Minya } \\
\hline Simulation Weather File & \multicolumn{2}{|c|}{ EGY_MINYA_623870_IW2.PRN (ASHRAE 2013) } \\
\hline Modeling Software & \multicolumn{2}{|c|}{ IDA Indoor Climate and Energy } \\
\hline House Type & \multicolumn{2}{|c|}{ Family house } \\
\hline Plot Area & \multicolumn{2}{|c|}{$300 \mathrm{~m}^{2}$} \\
\hline Glazing Type & \multicolumn{2}{|c|}{$20 \mathrm{~mm}$ single glazed glass, $\mathrm{U}$-value $=5.9 \mathrm{~W} /\left(\mathrm{m}^{2} \mathrm{~K}\right)$} \\
\hline External Walls & \multicolumn{2}{|c|}{$\begin{array}{l}5 \mathrm{~mm} \text { Plaster }+25 \mathrm{~mm} \text { Egyptian Portland cement mortar }+250 \mathrm{~mm} \text { Double red brick }+ \\
25 \mathrm{~mm} \text { Egyptian Portland cement mortar }+5 \mathrm{~mm} \text { Plaster. U-value }=1.546 \mathrm{~W} /\left(\mathrm{m}^{2} \mathrm{~K}\right)\end{array}$} \\
\hline Internal Walls & \multicolumn{2}{|c|}{$\begin{array}{l}5 \mathrm{~mm} \text { plaster }+25 \mathrm{~mm} \text { Egyptian Portland cement mortar }+125 \mathrm{~mm} \\
\text { single red brick }+25 \mathrm{~mm} \text { Egyptian Portland cement mortar }+5 \mathrm{~mm} \text { plaster U-value }= \\
2.281 \mathrm{~W} /\left(\mathrm{m}^{2} \mathrm{~K}\right)\end{array}$} \\
\hline Internal Floors & \multicolumn{2}{|c|}{$\begin{array}{l}10 \mathrm{~mm} \text { concrete tiles }+20 \mathrm{~mm} \text { Egyptian Portland cement mortar }+50 \mathrm{~mm} \text { sand }+200 \\
\mathrm{~mm} \text { plain concrete. U-value }=1.824 \mathrm{~W} /\left(\mathrm{m}^{2} \mathrm{~K}\right)\end{array}$} \\
\hline Roof & \multicolumn{2}{|c|}{$\begin{array}{l}10 \mathrm{~mm} \text { concrete tiles }+20 \mathrm{~mm} \text { Egyptian Portland cement mortar }+50 \mathrm{~mm} \text { sand }+20 \\
\mathrm{~mm} \text { betomine damp insulation }+150 \mathrm{~mm} \text { rein force concrete. U-value }=1.707 \mathrm{~W} /\left(\mathrm{m}^{2} \mathrm{~K}\right)\end{array}$} \\
\hline External Floor & \multicolumn{2}{|c|}{$\begin{array}{l}10 \mathrm{~mm} \text { Concrete tiles }+50 \mathrm{~mm} \text { sand }+20 \mathrm{~mm} \text { Egyptian Portland cement mortar }+200 \\
\mathrm{~mm} \text { plain concrete }+250 \mathrm{~mm} \text { soil. U-value }=1.172 \mathrm{~W} /\left(\mathrm{m}^{2} \mathrm{~K}\right)\end{array}$} \\
\hline Basement Wall Towards Ground & \multicolumn{2}{|c|}{$\begin{array}{l}5 \mathrm{~mm} \text { Plaster }+25 \mathrm{~mm} \text { Egyptian Portland cement mortar }+250 \mathrm{~mm} \text { double red brick }+ \\
25 \mathrm{~mm} \text { Egyptian Portland cement mortar }+5 \mathrm{~mm} \text { plaster. U-value }=1.546 \mathrm{~W} /\left(\mathrm{m}^{2} \mathrm{~K}\right)\end{array}$} \\
\hline Infiltration & \multicolumn{2}{|l|}{$7 \mathrm{ACH}$} \\
\hline & \multicolumn{2}{|c|}{ - $\quad$ Occupant: Activity level 1.0 MET } \\
\hline & \multicolumn{2}{|c|}{$\begin{array}{l}\text { Constant clothing } 0.85 \pm 0.25 \mathrm{CLO} \text { (clothing is automatically adapted between limits to } \\
\text { obtain comfort) } \\
\text { Occupancy time: }\end{array}$} \\
\hline & \multicolumn{2}{|c|}{$\begin{array}{l}\text { 1- Living room: fully present (1) [7:00-8:00, 17:00-22:00], half present (0.5) } \\
\text { [15:00-17:00], } 0 \text { otherwise, } \\
\text { 2- Bedroom 0 [7:00-22:00], } 1 \text { otherwise (remaining) }\end{array}$} \\
\hline & \multicolumn{2}{|c|}{ Emitted heat per person $75 \mathrm{~W}$} \\
\hline & $-\quad$ Eqr & ment usage time: \\
\hline \multirow[t]{6}{*}{ Internal Gains } & & $\begin{array}{l}\text { Living room: full intensity } 1 \text { [7:00-8:00, 17:00-22:00], half intensity } 0.5 \\
\text { [15:00-17:00], }\end{array}$ \\
\hline & $2-$ & Bedroom: $0[7: 00-22: 00], 1$ otherwise \\
\hline & \multicolumn{2}{|c|}{ Luminous efficiency $12 \mathrm{~lm} / \mathrm{W}$} \\
\hline & \multicolumn{2}{|c|}{ - $\quad$ Artificial lighting use: } \\
\hline & 1- & $\begin{array}{l}\text { living room From } 1 \text { Jan to } 14 \text { Apr all days: } 1 \text { [7:00-8:00, 17:00-22:00], } \\
\text { 0.5[15:00-17:00], } 0 \text { otherwise From } 16 \text { Oct to } 31 \text { Dec all days:1[7:00-8:00, } \\
\text { 17:00-22:00], 0.5[15:00-17:00], } 0 \text { otherwise From } 15 \text { Apr to } 15 \text { Oct all days:1 } \\
\text { [19:00-22:00], } 0 \text { otherwise All days: } 0\end{array}$ \\
\hline & 2- & $\begin{array}{l}\text { Bedroom From } 1 \text { Jan to } 14 \text { Apr all days:1 [6:00-7:00, 22:00-23:00], } \\
0 \text { otherwise From } 16 \text { Oct to 31Dec all days:1 [6:00-7:00,22:00-23:00], } \\
0 \text { otherwise All days: } 0\end{array}$ \\
\hline Schedules & \multicolumn{2}{|c|}{ Independ in different spaces } \\
\hline Daylight & \multicolumn{2}{|c|}{ Meteonorm database diffuse and direct radiation $\left(\mathrm{W} / \mathrm{m}^{2}\right)$} \\
\hline HVAC & \multicolumn{2}{|c|}{$\begin{array}{l}\text { No mechanical ventilation. Generic heating and cooling in the zones to compensate } \\
\text { heat losses and loads. }\end{array}$} \\
\hline
\end{tabular}

In the following, four different simplification scenarios of the thermal zones are proposed as shown in Figure 2. Summary of the simulated scenarios is presented in Table 2. First, in the base scenario (BS) model, each space is modeled as a single independent zone (Figure 1). Then, scenario S1 combines spaces with similar characteristics (e.g., orientation, operation schedules, same use, etc.) into one thermal zone (Figure 2). Then, scenario S2 combines the same oriented spaces for all of the 4 floors 
into one thermal zone (Figure 2). In scenario S3, all spaces on the same floor are merged into one single zone, and scenario S4 models the entire building as one single thermal zone (Figure 2).
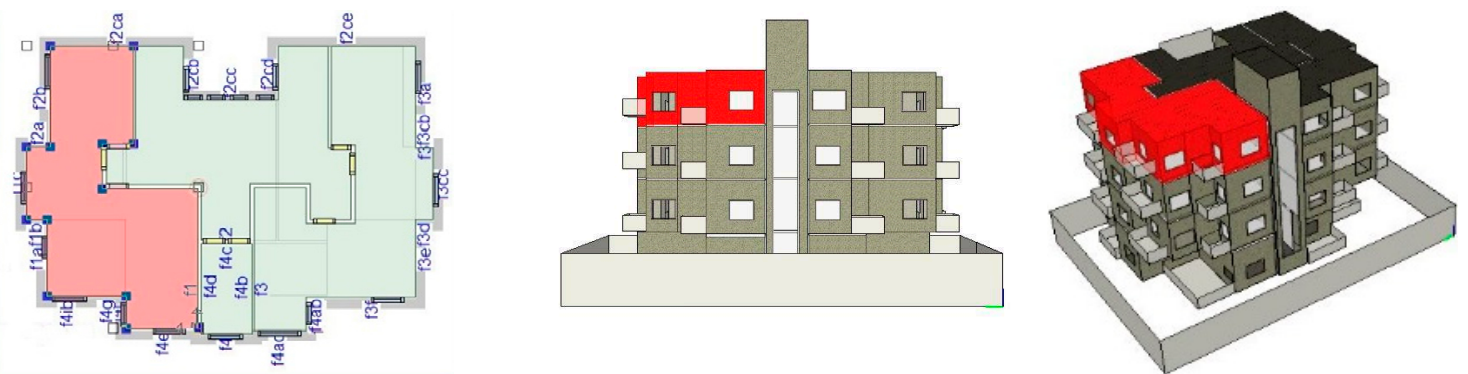

Scenario (S1)
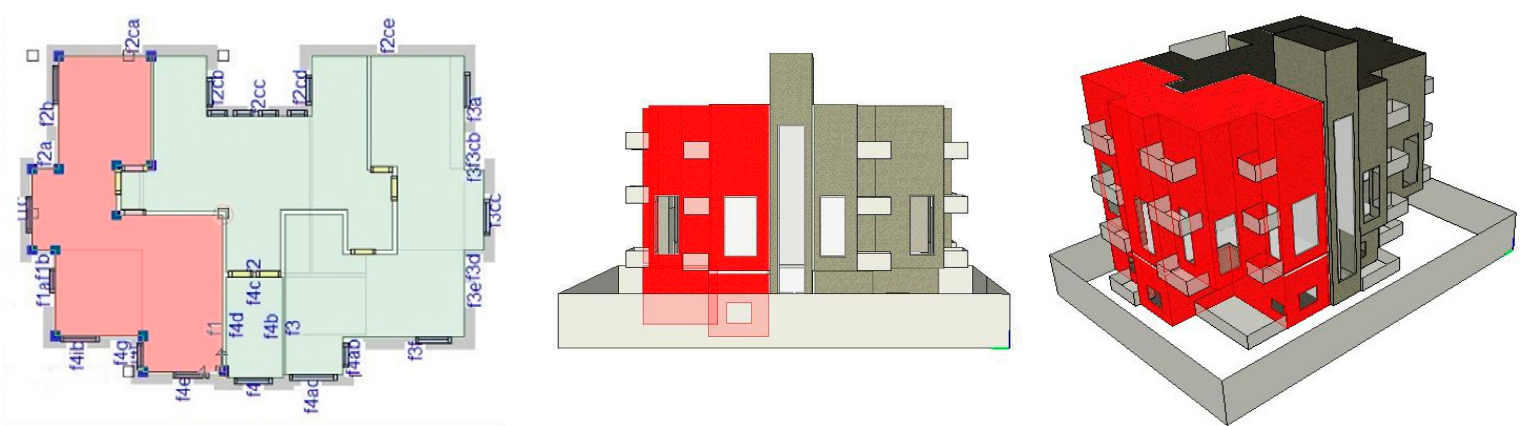

Scenario (S2)
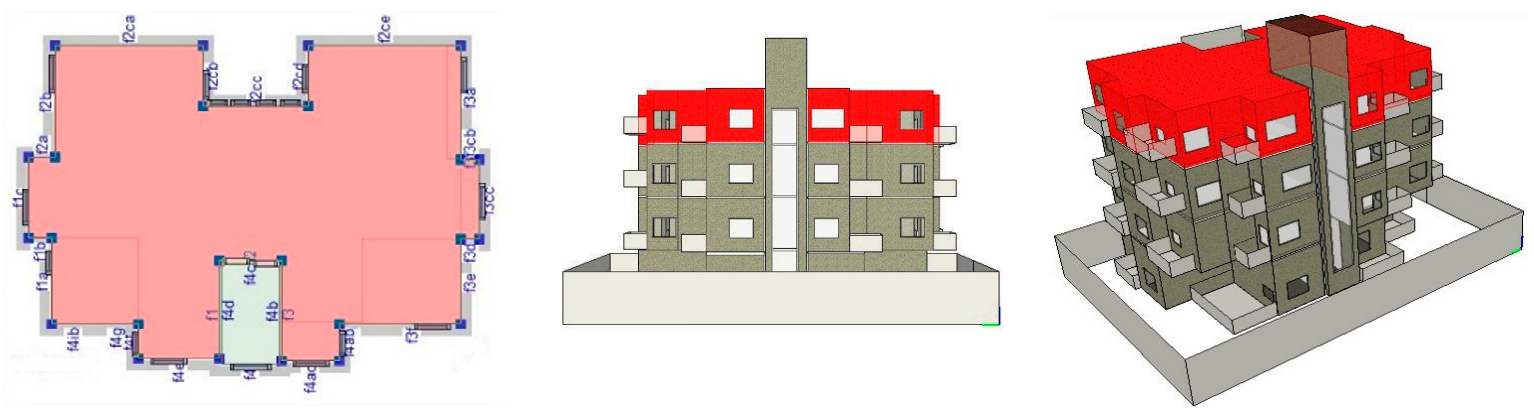

Scenario (S3)
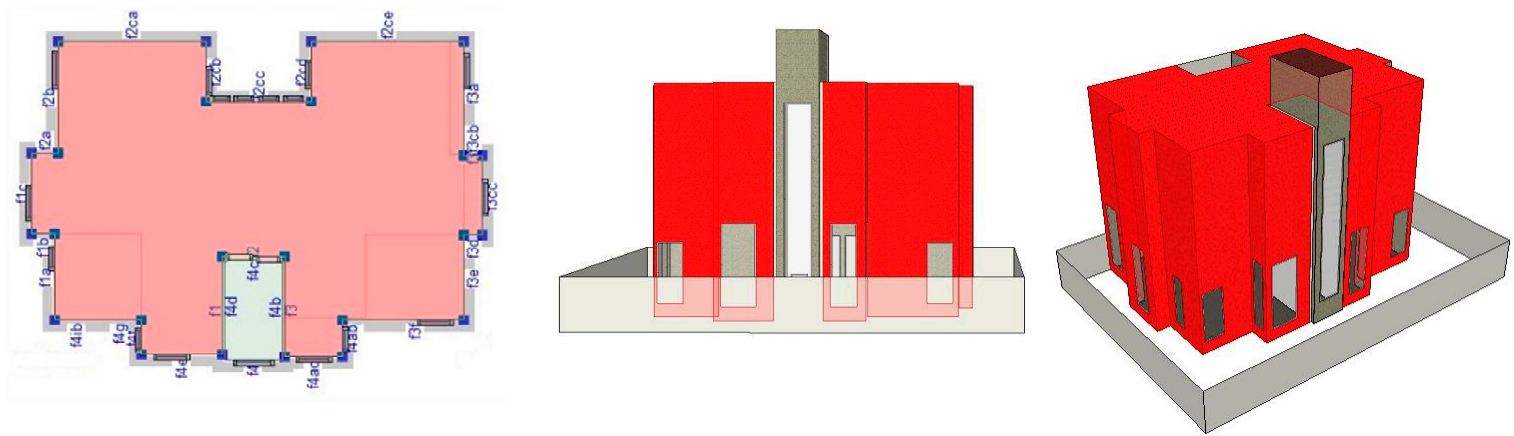

Figure 2. Simplification scenarios—simulation models (plan, side, and 3D view). 
Table 2. Simulated simplification scenarios.

\begin{tabular}{ccc}
\hline Scenario & Description of Investigated Thermal Zones & Number of Thermal Zones \\
\hline BS & $\begin{array}{c}\text { Base model: Each building space is modeled as a single zone. } \\
\text { Floor by floor, all identically oriented spaces with the same function are } \\
\text { merged into one zone with the same operation schedules, use, etc. } \\
\text { The same oriented spaces with the same use for all of the 4 floors are } \\
\text { combined into one thermal zone, i.e., bedrooms on ground floor, 1st floor, 2nd } \\
\text { floor, and 3rd floor are merged with circulation areas into one thermal zone. } \\
\text { All rooms on the same floor are merged into one thermal zone, thus in this } \\
\text { Scenario the whole building has 4 zones. }\end{array}$ & 64 \\
S3 & $\begin{array}{c}\text { The entire building is modeled as one single thermal zone. } \\
\text { S4 }\end{array}$ & 4 \\
\hline
\end{tabular}

\section{Results and Discussion}

\subsection{Building-Energy Assessment}

IDA ICE has been used to simulate energy consumption and indoor comfort performance of the studied building for the BS model and all the simplification scenarios. Figure 3 summarizes the energy results for the BS model and the simplification scenarios in comparison to BS model. The simplification scenarios have minor effect on the lighting, facility, equipment, tenant, and DHW results due to their similar input parameter and cumulated settings. On the other hand, electric cooling and heating show larger differences. In BS scenario, the cooling demand accounts to $67 \%$ of the total energy consumption, while the heating demand attributes to $18 \%$, as the case study located in a hot and dry climate. Lighting, facility, equipment, tenant and DHW accounted to 15\% of the total energy consumption. In S1, the cooling demand increased by $9.6 \%$ and the heating demand decreased by $3.1 \%$ with respect to BS (Table A1). S2 and S3 scenarios performed an increased cooling demand by $15.1 \%$ and $10.6 \%$ respectively, while the heating demand decreased by $3.5 \%$ and $0.3 \%$, respectively, compared to BS (Table A1). In scenario S4, the heating demand decreased by $23.6 \%$ in respect to BS model, while the cooling demand increased by $12.2 \%$ compared to BS (Table A1). Similar reports of the simplification on the energy performance are available in the literature, e.g., Heo et al. [34] and Ren et al. [41] have reported that merging rooms with similar characteristics into one zone (scenario S1) and modeling a single zone for the entire building (scenario S4) underestimated the annual heating demand by $7 \%$ and $24 \%$, respectively, in comparison to modeling every room as a separate zone (detail model) for domestic buildings in UK. Picco et al [17] have also reported that cooling and heating loads was underestimated by $9.29 \%$ and $8.12 \%$, respectively for scenario S3 (Every floor was represented by one individual zone) compared to the detailed model in an office building built, located in Bolzano, Italy. Picco and Marengo [16] have reported similar finding of simplification on cooling and heating demands. They reported that when the number of thermal zones are reduced to one thermal zone per floor (scenario S3), the annual heating and cooling demand are underestimated by $0.86 \%$ and $6.25 \%$, respectively. Consistent with the present result, Dipasquale et al. [35] have also reported that reducing the whole floor to one thermal zone underestimated the annual heating and cooling demand by $12.5 \%$ and $22 \%$, respectively with respect to the detailed model. Korolija, and Zhang [32] have also reported that treating each floor of a house as a single thermal zone underestimated the annual heating demand by $10.6 \%$. The change in the total energy consumption evolved in the first, second, third, and the fourth scenarios as follows, $+5.8 \%,+9.5 \%,+7.1 \%,+4.0 \%$ in respect to the BS model (Table A1). Although the fourth scenario represented the worst scenario considering only the cooling and heating demand individually, it had the smallest change in total energy consumption compared to BS model, because the heating and cooling deviations equaled each other out, resulting in the least difference in total. The thermal envelope is the same in all of the models, hence the fundamental differences can be derived from the complexity level of the actual modeled thermal mass, (walls, slabs) that affect mostly the cooling and heating demand, although the geometrically "missing" thermal mass was added to the model variations as individual mass elements respectively. Case S4's lowest heating demand is caused by the least floor space to be heated. 


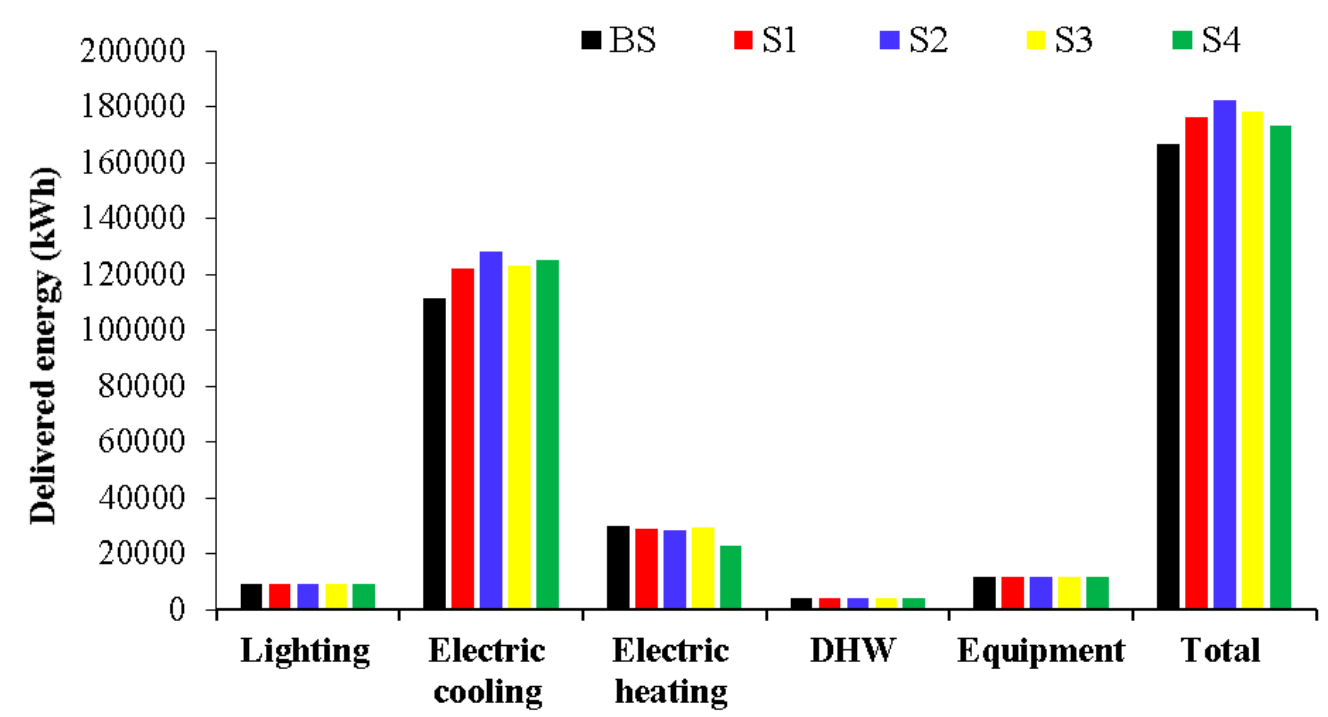

Figure 3. Delivered energy for the detailed and simplified models.

\subsection{Simulation Time and Modeling Time}

The total modeling time of the BS model was $215 \mathrm{~min}$, while it decreased to 45, 35, 22, and 11 minutes in the simplification scenarios, as shown in Table 3. The most decisive difference in modeling expenditure of time takes place in modeling of one story of a building, since multifamily houses possess a great diversity of apartment sizes, room arrangements and room geometries. After completion of a floor, the typically identic domestic levels can be copied above each other to complete the building model; therefore, this modeling work duration is insignificant. As the number of thermal zones are reduced in a story, the simulation time decreases decisively. Considering the geometry and structure creation as well as the editing and parametrization working time, the required modeling time is approx. proportional-with a rate of 1:1 — to the number of zones. At the same time, the total simulation time of the BS model was 86 minutes, and it decreased to 32,14, 23, and 5 minutes in the scenarios. With a decreasing number of thermal zones, the simulation time decreases significantly. The scenarios saved 79 to $95 \%$ of the modeling time and 63 to $94 \%$ calculation duration compared to BS, demonstrating a huge potential in model simplification and workflow conservation.

Table 3. Modeling and calculation duration of the detailed and simplified models and respective differences.

\begin{tabular}{lccccc}
\hline & BS & S1 & S2 & S3 & S4 \\
\hline Modeling time (Minutes) & 215 & 45 & 35 & 22 & 11 \\
Modeling time difference (\%) & 0 & -79 & -84 & -90 & -95 \\
\cline { 2 - 6 } Calculation time (Minutes) & 86 & 32 & 14 & 23 & 5 \\
Calculation time difference (\%) & 0 & -63 & -84 & -73 & -94 \\
\hline
\end{tabular}

\subsection{Assessment of Building Thermal Comfort}

\subsubsection{Evaluation of Predicted Mean Vote (PMV)}

In this study, PMV was evaluated as one of the main indices to assess the thermal comfort in an occupied zone [42,43]. PMV refers to thermal 7-stage sensation scale [44] through seven points range from -3 to +3 as follow $-3=$ cold,$-2=$ cool, $-1=$ slightly cool, $0=$ neutral, $1=$ slightly warm, $2=$ warm, and $3=$ hot [45]. Three categories A, B, and C were proposed in ISO 7730, PMV is ranged in the interval of $[-0.2,+0.2]$; for Category $A$, in the interval $[-0.5,+0.5]$ for Category $B$ and, in the interval $[-0.7,+0.7]$ for Category C [46]. Category B represents the normal level of applicability based on ISO 7730. Figure 4 shows the average number of annual hours of PMV, category B in the detailed 
and simplified models' separated as well as merged thermal zones. In the simplified models, the average annual hours of PMV, category B is calculated by an area weighted averaging of the annual hours of PMV, category B for each thermal zone, as presented in Equation (1)

$$
N_{P M V}=\frac{\sum_{i=1}^{i=n} N_{i} \cdot A_{i}}{\sum_{i=1}^{i=n} A_{i}}
$$

where $N_{P M V}$. means the average annual hours of PMV, category B for the whole model, $N_{i}$ represents the number of annual hours of PMV, category B for thermal zone $i, A_{i}$ the total area of each thermal zone $\left[\mathrm{m}^{2}\right]$, " $n$ " is the total number of thermal zones of the model. For the complete building in BS, the annual hours of PMV, category B were $7781 \mathrm{~h}$, while 6642 were accounted for S1. The annual hours of PMV, category B increased by 6 hours for S2 and, while the annual hours decreased by 875 and 64 hours for S3 models and one-zone model (S4), respectively compared to the BS model, as shown in Table A2. In S2, the difference in the annual hours of PMV, category B increased by 3.2\% in the south side and decreased by $29.3 \%$ in the north side, related to the BS model (Table A2). Reason for that: in the south oriented zone, solar gains enabled higher level of PMV, while in the north zone, the contrary effect evolved, because the high thermal zones (3-storey high) are more difficult to heat. In S3, the PMV decreased by $4.7 \%$ and $1.7 \%$ on the 2 rd floor and the 3nd floor respectively, with respect to BS. Reason for that: in the 3rd floor the highest zone is the warmest in summer because of thermal gradient and less thermal mass. However, this greatest deviation is more still at a marginal scale, hence, in general, a consistent calculated thermal comfort sensation was observed in each model.

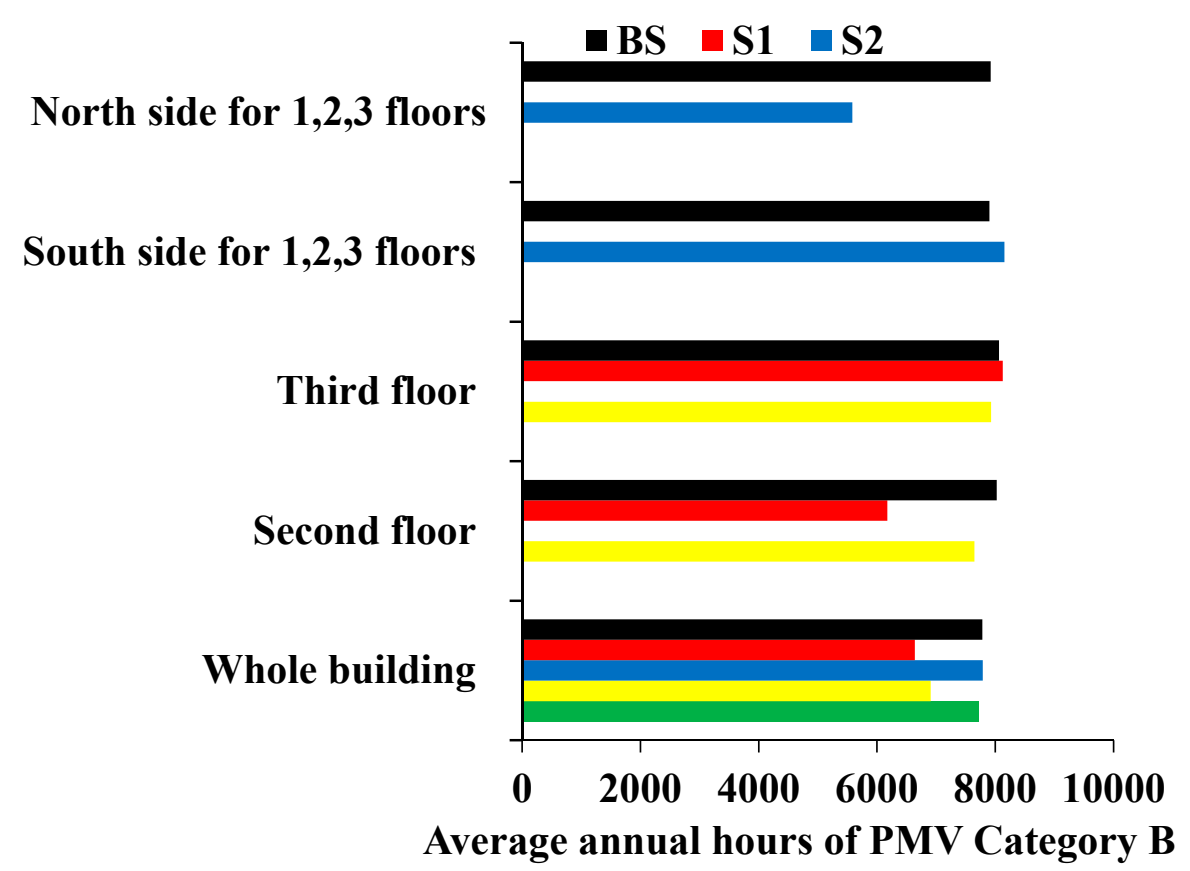

Figure 4. Average number of annual hours of PMV, Category B for whole and some parts of the building in the detailed.

\subsubsection{Carbon Dioxide Level Assessment}

Concentration of Carbon Dioxide $\left(\mathrm{CO}_{2}\right)$ was applied as an indicator of indoor air quality [47]. The connection between indoor air quality and indoor $\mathrm{CO}_{2}$ concentration originates from the fact that at the same time people are generating odor-causing bio effluents and producing $\mathrm{CO}_{2}$ [47]. In European Standard CEN-EN 13779:2007 [48], $\mathrm{CO}_{2}$ concentration is also applied to classify indoor air quality, and the maximum value of $\mathrm{CO}_{2}$ concentration level is $1500 \mathrm{ppm}$, while they recommend keeping $\mathrm{CO}_{2}$ concentration level below $1000 \mathrm{ppm}$. In this particular study, the number of annual hours is estimated, 
when the $\mathrm{CO}_{2}$ concentration level is above $1000 \mathrm{ppm}$ in the models. The results are compared at three scales (i.e., whole building, 2nd and 3rd floors, south and north sides of the building in all floors). Figure 5 presents the annual hours with $\mathrm{CO}_{2}$ concentration level above $1000 \mathrm{ppm}$ in the detailed and simplification models. Additionally, an area weighting such as Equation (1) was used to calculate average annual hours of $\mathrm{CO}_{2}$ concentration level. Regarding to the complete building, the number of annual hours of $\mathrm{CO}_{2}$ level above $1000 \mathrm{ppm}$ in BS scenario was $2248 \mathrm{~h}$, while S1 was accounted to $2130 \mathrm{~h}$. In the scenarios S2, S3, and S4 this value decreased by $7.2 \%, 8.4 \%$, and $5.9 \%$, respectively, compared to the BS scenario Table A3. Consistent with the present result, Korolija and Zhang [32] have also reported that treating each floor of a house as a single thermal zone (scenario S3) underestimated the carbon emission by $8 \%$. In scenarios S1 and S3, the differences in the air quality were $0.1 \%$ and $21.7 \%$ respectively in the second floor, while $48.9 \%$ and $8.7 \%$, differences occurred in third floor. In the south side of the whole building (S2 - building high thermal zone), the air hygiene decreased by $17.4 \%$ at the north side of the building with respect to the BS scenario while and the south side accounted to the same hours of BS scenario (Table A3). The merged, simplified zones have more space to be window-ventilated, since they include the corridors and secondary spaces (elevator/stairs) as well. That is why they perform higher $\mathrm{CO}_{2}$ level. Generally, the distribution of $\mathrm{CO}_{2}$ concentration shows great inhomogeneity in the different sized thermal zones.

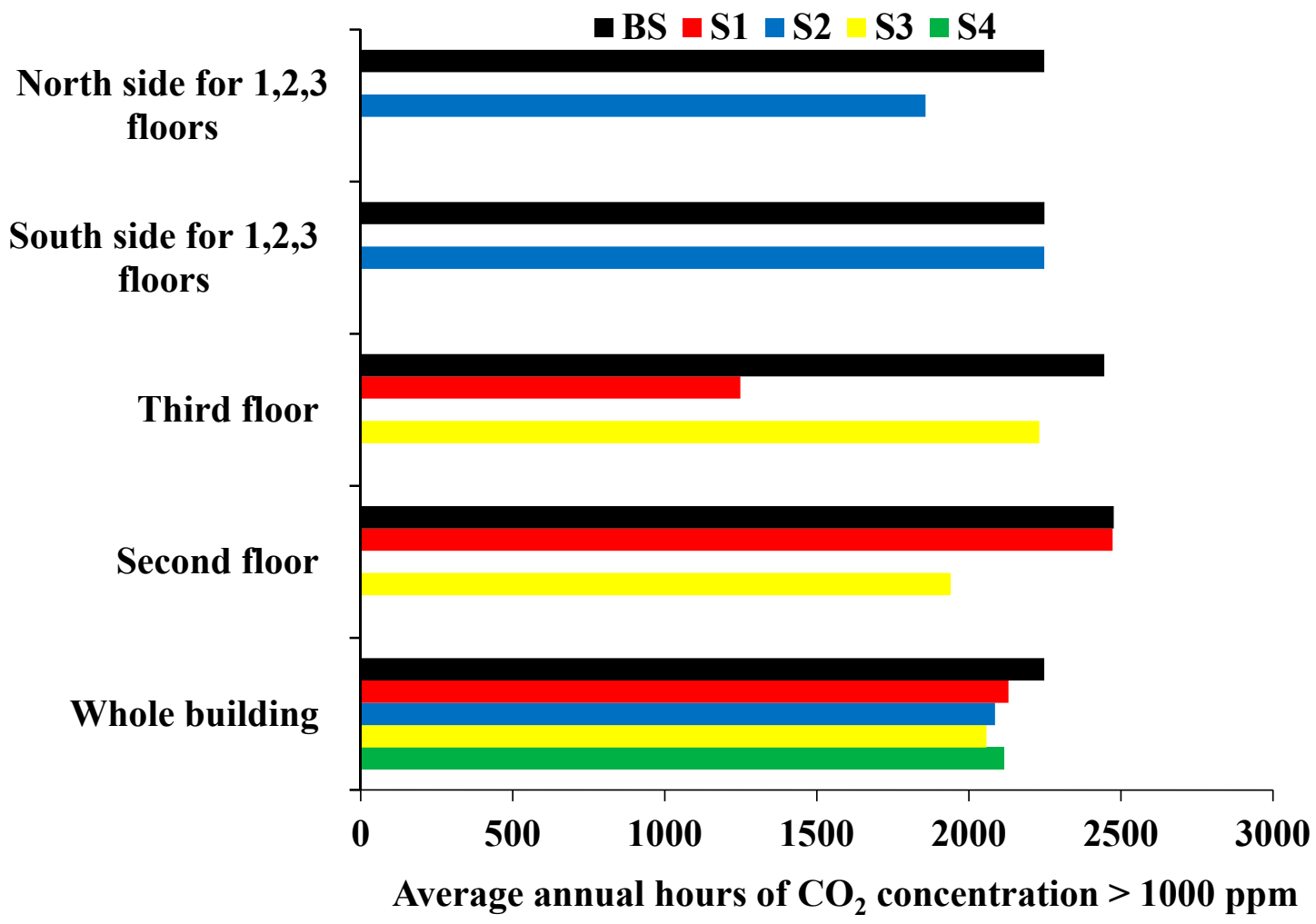

Figure 5. Average number of annual hours with $\mathrm{CO}_{2}$ concentration $>1000 \mathrm{ppm}$ for the whole and some parts of the building in the detailed and simplified models.

\subsubsection{Daylight Factor Assessment}

Daylighting as visual comfort is an effective parameter in sustainable and energy efficient building design [49] and it is becoming an essential part of the environmentally friendly building design [50]. Adequate level of daylight is not only important to illuminate all year long and secondarily to heat in wintertime the interior, but it is also an essential source of the occupant's emotional and physiological well-being. Besides ensuring low level of odor and noise, daylight provision is an essential parameter in indoor environment investigations for maintaining the enjoyment of a property. Daylighting performance strongly relies on the illuminance under direct, respectively diffuse sky conditions. 
Since the daylight provision under direct illuminance (clear sky conditions) in Minia region possesses high level of daylight autonomy in interior spaces, in this study, the visual comfort assessment focused on the Daylight Factor (DF), representing the illuminance performance of the spaces under mixed sky circumstances, as a kind of 'worst-case scenario'. Satisfying the minimum required DF limit means a whole year long secured daylighting quality. The DF value is a ratio that represents the amount of illuminance available indoors relative to the illuminance level present outdoors at the same time, under overcast sky [51]. DF at a point of the room is the ratio of the indoor illuminance Ei to the outdoor horizontal illuminance, Eo, [52], expressed as percentage in the following Equation (2):

$$
\mathrm{DF}=\frac{E_{i}}{E_{0}} \times 100[\%]
$$

Calculating Equation (2), the required value of DF for Minia city is 2.1, by applying the required Ei as 300 lx and Eo (median external diffuse illuminance) as 14012 lx according to EN17037 Daylight in Buildings and ASHRAE database. The DF was assessed in all models. Illuminances were computed using meteorological data taken from Meteonorm 7 database [53]. Figure 6 presents the ratio of floor area performing a DF above (corresponding to adequate daylight space partition) and below (equals to inadequate daylight space partition) the DF (2.1) threshold value. In case of BS, $21.3 \%$ the floor area is adequately daylight. In S1 and S3 the appropriately daylight floor area increased by $6.1 \%$ and $21.6 \%$ with respect to BS, while in S2 and S4 delivered significant, $19.8 \%$ and $60.3 \%$ differences compared to the reference. In $\mathrm{S} 1$ the abandonment of all internal walls caused the weaker DF performance and in S3 the additionally merged, deep spaces of the whole story thermal zones indicated the lower level of DF. The reason of the anomalies in S2 and S4 were the different height of the zones in the S2 and S4 models.

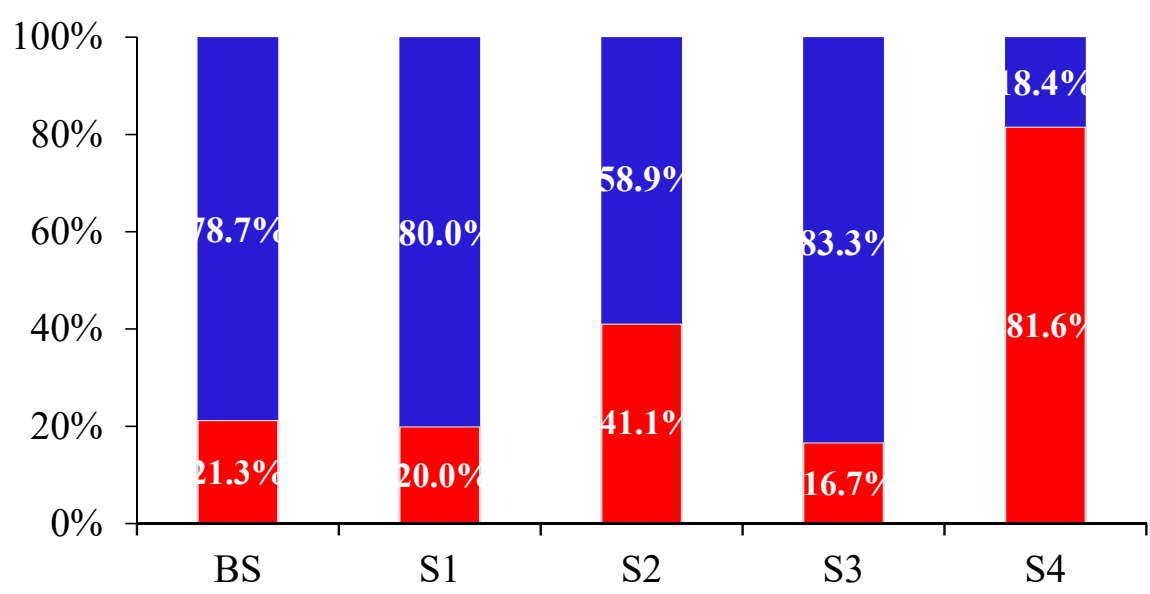

Figure 6. Floor area ratio with daylight factor above (red color) and below (blue color) the minimum DF $(2.1 \%)$ value.

\section{Optimal Scenario of the Proposed Model Simplifications}

To determine the optimal scenario of the proposed simplifications, two crucial criteria should be taken into account: the required simulation time and the accuracy of the energy and comfort results. In respect to calculation duration, obviously the single-zone model (S4) represents the fastest model as shown in Table 3, followed by S2 model, S3 model, and S1 model. For the accuracy criteria, Table 4 presents the absolute differences of energy demand (heating and cooling) and indoor comfort (PMV, $\mathrm{CO}_{2}$ level and DF) in respect to the BS model. More simplification leads to more inaccurate results, as in S4 model the high differences in energy demand and DF distribution demonstrate. In comparison to BS, (S1) presented the optimal accuracy case of the proposed simplification scenarios, resulting in $6.8 \%$ average difference of all parameters in energy demand and comfort performance. At the same time, S1 saves over $63 \%$ of simulation time. S1 is followed by scenarios 3, 2, and 4 . Consequently, the model simplification can be accomplished until the anomalies appear due to the simplified geometry. 
Table 4. Absolute \% differences of heating and cooling demand, $\mathrm{PMV}, \mathrm{CO}_{2}$ concentration, and DF between the simplification scenarios and BS.

\begin{tabular}{|c|c|c|c|c|}
\hline \multirow[t]{3}{*}{ Parameter } & \multicolumn{4}{|c|}{ Simplification Scenarios } \\
\hline & \multicolumn{4}{|c|}{ Absolute \% Differences with Respect to the BS } \\
\hline & S1 & S2 & S3 & $\mathrm{S} 4$ \\
\hline Heating Demand & 3.1 & 3.5 & 0.3 & 23.6 \\
\hline Cooling Demand & 9.6 & 15.1 & 10.6 & 12.2 \\
\hline PMV & 14.6 & 0.1 & 11.3 & 0.8 \\
\hline $\mathrm{CO}_{2}$ Concentration & 5.3 & 7.2 & 8.4 & 5.9 \\
\hline DF & 1.5 & 20.1 & 4.5 & 56.6 \\
\hline Average Differences & 6.8 & 9.2 & 7.0 & 19.8 \\
\hline Order & 1 & 3 & 2 & 4 \\
\hline$\%$ Save in Simulation Time & 63 & 84 & 73 & 94 \\
\hline
\end{tabular}

\section{Conclusions}

Buildings are attributed to a tremendous amount of energy consumption due to their continuous operation and extensive lifetime. Performing Building-energy simulations is an essential part of a decision-making process as it helps designers to assess the energy and comfort effect of different building design options. Since the impacts of building physics simulation model simplifications on the accuracy of the results are not well studied and reported, the proposed simplification scenarios seek to overcome the obstacle of long calculation time and according design costs by providing a simpler and faster way to carry out building-energy and comfort simulations. The main aspect of the methodology is to achieve an adequate level of accuracy that can promote the simulation results of energy demand and thermal comfort analysis by simultaneously minimizing calculation time. The detailed reference building physics simulation model contained all separate rooms modeled as individual thermal zones. The model was then simplified in scenario S1, whereas all spaces with similar use and orientation were merged into one-zone floor by floor. The same oriented spaces for all of the 4 floors were combined into one thermal zone in scenario S2. Every floor was represented by one individual zone in scenario S3, and the whole building was treated as one single zone for scenario S4. Multiple effects of the model simplification methods on energy consumption, $\mathrm{CO}_{2}$ level, $\mathrm{PMV}$, and DF performance were evaluated in a common residential building in New Minia, Egypt.

A model simplification method that merges all spaces with similar use and orientation into one-zone floor by floor (scenario S1), enables the shortening of the required modeling time of $79 \%$ and the acceleration of the required solver calculation duration by $63 \%$. At the same time, the comfort performance values possess $21.4 \%$ deviations, while the energy performance results are underestimated by $12.7 \%$ in comparison to the detailed model. Combining the same oriented spaces with the same use for all of the 4 floors into one thermal zone (scenarios S2) reduces the simulation time by $84 \%$, while the deviation in total energy demand and thermal comfort are $18.6 \%$ and $27.4 \%$, respectively, compared to the detailed model. When the number of thermal zones is further reduced to one thermal zone per floor (scenarios S3), the simulation time is saved by $73 \%$, while the energy and thermal comfort are underestimated by $10.9 \%$ and $24.2 \%$. However, modeling the entire building by a single zone (scenarios S4) saves $95 \%$ and $94 \%$ of the required modeling time and the simulation time, respectively, the energy and thermal comfort are underestimated by $35.8 \%$ and $63.3 \%$, respectively. The interdependency of result accuracy and calculation time proved that the optimal simplification method merges all spaces with similar use and orientation into one-zone floor by floor (scenario S1). It is obvious that besides the advantages the geometrical simplifications might carry some limitations as well. Results showed that thermal zone merging as a simulation simplification method has its limitations as well, whereas a too intensive simplification can lead to undesired error rates. Furthermore, the essentially geometry related daylight distribution interpretation can be affected due to the different depth of the merged zones. In addition, the orientation should be considered with consciousness, since the different oriented zones 
should not be combined to avoid different solar heat load (summer) or heat gain (winter) effect to be mixed in one greater unified zone to confuse both energy and comfort behavior.

Important to mention that taking only the energy results into consideration during the simplification process is not sufficient to get a truly comparable model version to the original detailed building model, rather it is inevitable to consider all determinate indoor comfort indices as well. Analysis of both comfort and energy results is the only way to identify the optimum on model simplification level. The gained thermal zoning simplification method can imply a high design feedback acceleration effect, offering a great potential for building design optimization. An until now unreached quality level of design optimization evolves, since testing of significantly higher number of design cases in the same amount of available planning time is getting to be possible. The thermal zone geometry simplification's result inaccuracy level should be further reduced by compensation solutions for thermal mass and the central, deeper settled zone sections, which distort to a certain measure the simulation results. The described methodology can help to reduce the duration requirements for a dynamic simulation and it can be seen as a 1st step in a multi-level model simplification strategy, consisting of next stages in simplifications techniques for fenestration, shading, thermal mass, HVAC systems, as well as controlling automation strategies. It can be concluded that the analysis results will be useful for modelers to determine the optimal level of model simplification in the modeling process depending on the achievable accuracy level of energy performance and thermal comfort. The method provided promising results for further applications and it is intended to be further tested in next multifamily projects and office buildings to prove its reliability in building industry standard practice.

Author Contributions: Conceptualization, S.E.; Data curation, S.E., B.B. and C.H.R.; Formal analysis, S.E.; Methodology, S.E. and B.B.; Project administration, I.K. and B.B.; Software, S.E. and B.B.; Supervision, I.K., B.B. and J.G.; Validation, S.E. and C.H.R.; Visualization, I.K., B.B. and C.H.R.; Writing - original draft, S.E.; Writing - review \& editing, I.K., B.B., J.G. and C.H.R. All authors have read and agreed to the published version of the manuscript.

Funding: This research received no external funding

Acknowledgments: The present scientific contribution is dedicated to the 650th anniversary of the foundation of the University of Pécs, Hungary. The first author would like to thank the Egyptian Ministry of Higher Education (MoHE) and Tempus Public Foundation for providing him the Stipendium Hungaricum Scholarship. Further we appreciate the support of the János Szentágoghai Research Centre, University of Pécs, Energia Design Research Group, led by Prof Dr István Kistelegdi. The research project is conducted at the University of Pécs, Hungary, within the framework of the Biomedical Engineering Project of the Thematic Excellence Programme 2019 (TUDFO/51757-1/2019-ITM). The research project is conducted at the University of Pécs, Hungary, within the framework of the Biomedical Engineering Project of the Thematic Excellence Programme 2019 (TUDFO/51757-1/2019-ITM).

Conflicts of Interest: “The authors declare no conflict of interest."

\section{Appendix A}

Table A1. Delivered energy for detailed and simplified models and their differences with respect to detailed model.

\begin{tabular}{cccccc}
\hline Delivered Energy & BS & S1 & S2 & S3 & S4 \\
\hline Lighting, Facility (kWh) & 9199 & 9209 & 9213 & 9205 & 9205 \\
Difference \% & 0 & 0.1 & 0.1 & 0.1 & 0.1 \\
Electric Cooling (kWh) & 111,501 & 122,223 & 128,313 & 123,326 & 125,104 \\
Difference \% & 0 & 9.6 & 15.1 & 10.6 & 12.2 \\
Electric Heating (kWh) & 29,755 & 28,824 & 28,716 & 29,653 & 22,723 \\
Difference \% & 0 & -3.1 & -3.5 & -0.3 & -23.6 \\
DHW (kWh) & 4246 & 4246 & 4246 & 4246 & 4246 \\
Difference \% & 0.0 & 0.0 & 0.0 & 0.0 & 0.0 \\
Equipment, Tenant (kWh) & 11,746 & 11,764 & 11,750 & 11,753 & 11,761 \\
Difference \% & 0 & 0.2 & 0.0 & 0.1 & 0.1 \\
Total (kWh) & 166,447 & 176,166 & 182,237 & 178,182 & 173,038 \\
Difference \% & 0 & 5.8 & 9.5 & 7.1 & 4.0 \\
\hline
\end{tabular}


Table A2. Average number of annual hours of PMV, Category B for whole and some parts of the building in the detailed and simplified models and differences of simplified models with respect to detailed model.

\begin{tabular}{cccccc}
\hline & BS & S1 & S2 & S3 & S4 \\
\hline & \multicolumn{3}{c}{ Average Annual Hours of PMV Category B } \\
\cline { 2 - 6 } Whole Building (hours) & 7781 & 6642 & 7787 & 6906 & 7717 \\
Difference \% & 0.0 & -14.6 & 0.1 & -11.3 & -0.8 \\
Second Floor (hours) & 8026 & 6176 & - & 7646 & - \\
Difference \% & 0.0 & -23.1 & - & -4.7 & - \\
Third Floor (hours) & 8063 & 8128 & - & 7928 & - \\
Difference \% & 0.0 & 0.8 & - & -1.7 & - \\
South Side for 1,2,3 Floors (hours) & 7900 & - & 8153 & - & - \\
Difference \% & 0.0 & - & 3.2 & - & - \\
North Side for 1,2,3 Floors (hours) & 7921 & - & 5585 & - & - \\
Difference \% & 0.0 & - & -29.3 & - & - \\
\hline
\end{tabular}

- = Zero (no value), as there was no simulation in this zone for the given scenario.

Table A3. Average number of annual hours with $\mathrm{CO}_{2}$ concentration $>1000 \mathrm{ppm}$ for whole and some parts of the building in the detailed and simplified models and differences of simplified models with respect to detailed model.

\begin{tabular}{cccccc}
\hline & BS & S1 & S2 & S3 & S4 \\
\hline & \multicolumn{2}{c}{ Average } & annual hours & of $\mathbf{C O}_{\mathbf{2}}$ concentration $\mathbf{~} \mathbf{1 0 0 0}$ ppm \\
\cline { 2 - 6 } Whole Building (hours) & 2248 & 2130 & 2086 & 2058 & 2116 \\
Difference \% & 0.0 & -5.3 & -7.2 & -8.4 & -5.9 \\
Second Floor (hours) & 2476 & 2473 & - & 1940 & - \\
Difference \% & 0.0 & -0.1 & - & -21.7 & - \\
Third Floor (hours) & 2445 & 1249 & - & 2232 & - \\
Difference \% & 0.0 & -48.9 & - & -8.7 & - \\
South Side for 1,2,3 Floors (hours) & 2249 & - & 2248 & - & - \\
Difference \% & 0.0 & - & 0.0 & - & - \\
North Side for 1,2,3 Floors (hours) & 2248 & - & 1858 & - & - \\
Difference \% & 0.0 & - & -17.4 & - & - \\
\hline
\end{tabular}

- = Zero (no value), as there was no simulation in this zone for the given scenario.

\section{References}

1. Solangi, K.H.; Islam, M.R.; Saidur, R.; Rahim, N.A.; Fayaz, H. A review on global solar energy policy. Renew. Sustain. Energy Rev. 2011, 15, 2149-2163. [CrossRef]

2. International Energy Agency (IEA). World Energy Outlook 2012; Organisation for Economic Cooperation and Development (OECD): Paris, France, 2012; ISBN 978-92-64-18134-2.

3. Wolfram, C.; Shelef, O.; Gertler, P. How Will Energy Demand Develop in the Developing World? J. Econ. Perspect. 2012, 26, 119-138. [CrossRef]

4. Pérez-Lombard, L.; Ortiz, J.; Pout, C. A review on buildings energy consumption information. Energy Build. 2008, 40, 394-398. [CrossRef]

5. Malko, J. Energia dla wszystkich. Globalne wyzwanie dla sektora energii. Polityka Energetyczna 2015, 18, 5-13.

6. Keho, Y. What drives energy consumption in developing countries? The experience of selected African countries. Energy Policy 2016, 91, 233-246. [CrossRef]

7. Ürge-Vorsatz, D.; Eyre, N.; Graham, P.; Harvey, D.; Hertwich, E.; Jiang, Y.; Kornevall, C.; Majumdar, M.; McMahon, J.E.; Mirasgedis, S.; et al. Energy End-Use: Buildings. In Global Energy Assessment (GEA); Johansson, T.B., Nakicenovic, N., Patwardhan, A., Gomez-Echeverri, L., Eds.; Cambridge University Press: Cambridge, UK, 2012; pp. 649-760. ISBN 978-0-511-79367-7. 
8. Urban, B.; Glicksman, L. The mit design advisor-A fast, simple tool for energy efficient building design. In Proceedings of the Simbuild 2006 Second National IBPSA-USA Conference, Cambridge, MA, USA, 2-4 August 2006; pp. 270-276.

9. Elhadad, S.; Baranyai, B.; Gyergyák, J.; Kistelegdi, I.; Salem, A. Passive design strategies for residential buildings in a hot desert climate in upper Egypt. In Proceedings of the Multidisciplinary Scientific GeoConference SGEM 2019, Albena, Bulgaria, 28 June-7 July 2019; Volume 19, pp. 495-502.

10. Chen, A. Working Toward the Very Low Energy Consumption Building of the Future. Available online: https:/newscenter.lbl.gov/2009/06/02/working-toward-the-very-low-energy-consumption-buildingof-the-future/ (accessed on 19 March 2019).

11. Elhadad, S.; Rais, M.; Boumerzoug, A.; Baranyai, B. Assessing the impact of local climate on the building energy design: Case study Algeria-Egypt in hot and dry regions. In Proceedings of the International Conference, Istanbul, Turkey, 20-21 November 2019; pp. 21-24.

12. Economidou, M.; Atanasiu, B.; Despret, C.; Maio, J.; Nolte, I.; Rapf, O.; Laustsen, J.; Ruyssevelt, P.; Staniaszek, D.; Strong, D.; et al. Europe's Buildings under the Microscope: A Country by Country Review of the Energy Performance of Buildings; BPIE: Buildings Performance Institute of Europe: Brussels, Belgium, 2011; pp. 98-122.

13. Roberti, F.; Oberegger, U.F.; Lucchi, E.; Gasparella, A. Energy retrofit and conservation of built heritage using multi-objective optimization: Demonstration on a medieval building. In Proceedings of the Building Simulation Applications, Bolzano, Italy, 4-6 February 2015; pp. 189-197.

14. Elhadad, S.; Baranyai, B.; Gyergyák, J. Energy consumption indicators due to appliances used in residential building, A case study New Minia, Egypt. In Proceedings of the 6th International Academic Conference on Places and Technologies, Pécs, Hungary, 9-10 May 2019; pp. 188-193.

15. Becherini, F.; Lucchi, E.; Gandini, A.; Barrasa, M.C.; Troi, A.; Roberti, R.; Sachini, M.; Di Truccio, M.C.; Arrieta, L.G.; Pockelé, L.; et al. Characterization and thermal performance evaluation of infrared reflective coatings compatible with historic buildings. Build. Environ. 2018, 134, 35-46. [CrossRef]

16. Picco, M.; Marengo, M. On the Impact of Simplifications on Building Energy Simulation for Early Stage Building Design. J. Eng. Archit. 2015, 3, 66-78. [CrossRef]

17. Picco, M.; Lollini, R.; Marengo, M. Towards energy performance evaluation in early stage building design: A simplification methodology for commercial building models. Energy Build. 2014, 76, 497-505. [CrossRef]

18. Elhadad, S.; Baranyai, B.; Gyergyák, J. The impact of building orientation on energy performance: A case study in new Minia, Egypt. Pollack Period. 2018, 13, 31-40. [CrossRef]

19. Chatzivasileiadi, A.; Lannon, S.; Jabi, W.; Wardhana, N.M.; Aisha, R. Addressing Pathways to Energy Modelling Through Non-Manifold Topology. In Proceedings of the 2018 Symposium on Simulation for Architecture and Urban Design (SimAUD 2018), Delft, The Netherlands, 4-7 June 2018.

20. Fonseca, A.; Ortiz, J.; Garrido, N.; Fonseca, P.; Salom, J. Simulation model to find the best comfort, energy and cost scenarios for building refurbishment. J. Build. Perform. Simul. 2018, 11, 205-222. [CrossRef]

21. Zhao, J.; Wu, Y.; Shi, X.; Jin, X.; Zhou, X. Impact of Model Simplification at Geometric Modelling Stage on Energy for Office Building. In Proceedings of the 4th Building Simulation and Optimization Conference, (BSO 2018), Cambridge, UK, 11-12 September 2018; pp. 402-406.

22. Punjabi, S.; Miranda, V. Development of an integrated building design information interface. In Proceedings of the Ninth International IBPSA Conference 2005, Montréal, QC, Canada, 15-18 August 2005; p. 8.

23. Van Dijk, E.J.; Luscuere, P. An architect friendly interface for a dynamic building simulation program. In Proceedings of the Sustainable Building 2002 Conference, Oslo, Norway, 23-25 September 2002.

24. Gratia, E.; De Herde, A. A simple design tool for the thermal study of an office building. Energy Build. 2002, 34, 279-289. [CrossRef]

25. Attia, S.; Beltrán, L.; Herde, A.D.; Hensen, J. Architect friendly: A comparison of ten different building perfor-mance simulation tools. In Proceedings of the 11th International IBPSA Conference on Building Simulation, Glasgow, UK, 27-30 July 2009; pp. 204-211.

26. Liu, S.; Henze, G.P. Calibration of building models for supervisory control of commercial buildings. In Proceedings of the of the Ninth International IBPSA Conference 2005, Montreal, QC, Canada, 15-18 August 2005; p. 8.s.

27. Westphal, F.S.; Lamberts, R. Building simulation calibration using sensitivity analysis. In Proceedings of the Ninth International IBPSA Conference 2005, Montreal, QC, Canada, 15-18 August 2005; p. 8. 
28. Capozzoli, A. Impacts of architectural design choices on building energy performance applications of uncertainty and sensitivity techniques. In Proceedings of the 11th International IBPSA Conference on Building Simulation, Glasgow, Scotland, 27-30 July 2009; p. 9.

29. Smith, L.; Bernhardt, K.; Jezyk, M. Automated Energy Model Creation for Conceptual Design. In Proceedings of the 2011 Symposium on Simulation for Architecture and Urban Design, Boston, MA, USA, 4-7 April 2011.

30. Amitrano, L.; Isaacs, N.; Saville-Smith, K.; Donn, M.; Camilleri, M.; Pollard, A.; Babylon, M.; Bishop, R.; Roberti, J.; Burrough, L.; et al. Building Energy End-Use Study (BEES), Part 1: Final Report; BRANZ Study Report No. SR 297/1; BRANZ Ltd.: Judgeford, New Zealand, 2014.

31. Bosscha, E. Sensitivity Analysis Comparing Level of Detail and the Accuracy of Building Energy Simulations. Bachelor's Thesis, University of Twente, Enschede, The Netherlands, 2013. Available online: https: //purl.utwente.nl/essays/64511 (accessed on 12 April 2020).

32. Korolija, Y.D.Q.; Zhang, Y. Impact of model simplification on energy and comfort analysis for dwellings. In Proceedings of the 13th Conference of International Building Performance Simulation Association, Chambéry, France, 26-28 August 2013; pp. 1184-1192.

33. Klimczak, M.; Bojarski, J.; Ziembicki, P.; Kȩskiewicz, P. Analysis of the impact of simulation model simplifications on the quality of low-energy buildings simulation results. Energy Build. 2018, 169, 141-147. [CrossRef]

34. Heo, Y.; Ren, G.; Sunikka-Blank, M. Investigating an Adequate Level of Modelling for Energy Analysis of Domestic Buildings. In Proceedings of the 3rd Asia conference of International Building Performance Simulation Association - ASim2016, Jeju(Cheju) Island, South Korea, 27-29 November 2016.

35. Dipasquale, C.; Antoni, M.D.; Fedrizzi, R. The effect of the modelling approach on the building's loads assessment. In Proceedings of the Energy Forum on Advanced Building Skins, Bressanone, Italy, 5-6 November 2013.

36. Akkurt, G.G.; Aste, N.; Borderon, J.; Buda, A.; Calzolari, M.; Chung, D.; Costanzo, V.; Del Pero, C.; Evola, G.; Huerto-Cardenas, H.E.; et al. Dynamic thermal and hygrometric simulation of historical buildings: Critical factors and possible solutions. Renew. Sustain. Energy Rev. 2020, 118, 109509. [CrossRef]

37. Samuelson, H.W.; Ghorayshi, A.; Reinhart, C.F. Analysis of a simplified calibration procedure for 18 design-phase building energy models. J. Build. Perform. Simul. 2016, 9, 17-29. [CrossRef]

38. ASHRAE. ANSI/ASHRAE/IESNA Standard 90.1-2013 Energy Standard for Buildings Except Low Rise Residential Buildings; American Society of Heating, Refrigerating and Air-Conditioning Engineers: Atlanta, GA, USA, 2013.

39. Building Research Establishment Ltd. National Calculation Methodology (NCM) modelling guide (for buildings other than dwellings in England); Communities and Local Government: London, UK, 2013. Available online: https://www.uk-ncm.org.uk/filelibrary/NCM_Modelling_Guide_2013_Edition_20November2017.pdf (accessed on 12 April 2020).

40. Natural Resources Canada; CANMET Energy Technology Centre. EE4 Software Version 1.7: Modelling Guide; Natural Resources Canada: Ottawa, ON, Canada, 2008.

41. Ren, G.; Heo, Y.; Sunikka-Blank, M. Investigating an adequate level of modelling for retrofit decision-making: A case study of a British semi-detached house. J. Build. Eng. 2019, 26, 100837. [CrossRef]

42. Ho, S.H.; Rosario, L.; Rahman, M.M. Thermal comfort enhancement by using a ceiling fan. Appl. Therm. Eng. 2009, 29, 1648-1656. [CrossRef]

43. Ismail, A.R.; Jusoh, N.; Makhtar, N.K.; Zakaria, J.S.M.; Zainudin, M.K.; Omar, Z.C.; Ghani, R.A. Assessment of Thermal Comfort: A Study at Closed and Ventilated Call Centre. Am. J. Appl. Sci. 2010, 7, 402-407. [CrossRef]

44. Fanger, P.O. Thermal Comfort; Danish Technical Press: Copenhagen, Denmark, 1970.

45. Holmes, M.J.; Hacker, J.N. Climate change, thermal comfort and energy: Meeting the design challenges of the 21st century. Energy Build. 2007, 39, 802-814. [CrossRef]

46. Carlucci, S.; Pagliano, L. A review of indices for the long-term evaluation of the general thermal comfort conditions in buildings. Energy Build. 2012, 53, 194-205. [CrossRef]

47. Batog, P.; Badura, M. Dynamic of Changes in Carbon Dioxide Concentration in Bedrooms. Procedia Eng. 2013, 57, 175-182. [CrossRef] 
48. European Committee for Standardization (CEN)-EN 13779:2007. Ventilation for Non-Residential Buildings-Performance Requirements for Ventilation and Room-Conditioning Systems; European Committee for Standardization: Brussels, Belgium, 2007.

49. Ihm, P.; Nemri, A.; Krarti, M. Estimation of lighting energy savings from daylighting. Build. Environ. 2009, 44, 509-514. [CrossRef]

50. Kim, G.; Lim, H.S.; Lim, T.S.; Schaefer, L.; Kim, J.T. Comparative advantage of an exterior shading device in thermal performance for residential buildings. Energy Build. 2012, 46, 105-111. [CrossRef]

51. Waldram, P.J. The Natural and Artificial Lighting of Buildings. J. R. Inst. Br. Archit. 1925, 32, 405-426, 441-446.

52. Commission Internationale de l'Eclairage (CIE). Daylight; Technical Report No. CIE 016-1970; CIE CIE Central Bureau: Vienna, Austria, 1970; ISBN 9783901906664.

53. Meteotest, FabrikStrasse 14, CH-3012, Bern, Meteonorm 2000, Global Meteorological Database for Solar Energy and Applied Meteorology. Available online: https://www.thenbs.com/PublicationIndex/Documents/ Details?DocId=306747 (accessed on 20 February 2019).

(C) 2020 by the authors. Licensee MDPI, Basel, Switzerland. This article is an open access article distributed under the terms and conditions of the Creative Commons Attribution (CC BY) license (http://creativecommons.org/licenses/by/4.0/). 